\title{
An in vitro study on the effects of serum proteins on Enterococcus faecalis adhesion to three types of root sealers and gutta-percha
}

Xinwei Lin ${ }^{1,2}$, Danlu Chi ${ }^{1,2}$, Qimei Gong ${ }^{1,2}$ and Zhongchun Tong ${ }^{1,2^{*}}$

\begin{abstract}
Background: The extrusion of overfilled materials that extend beyond the apical foramina into the periradicular tissue may serve as a reservoir for bacterial adhesion and further affect recovery from periapical diseases. The aim of this study was to evaluate the effects of serum proteins on Enterococcus faecalis adhesion and survival on the surface of a calcium hydroxide-based root canal sealer (Apexit Plus), an epoxy resin sealer (AH-Plus) and a bioceramic sealer (iRoot SP).

Methods: Apexit Plus, AH-Plus and iRoot SP were evenly coated on gutta-percha, using gutta-percha alone as the control. After root canal sealer setting, the number of E. faecalis adhering to the root canal sealers and gutta-percha was counted in fetal bovine serum (FBS) or tryptic soy broth supplemented with $1 \%$ glucose (TSBG) by viable cell plate counts. The morphology of 7-day-old E. faecalis biofilms in FSB and TSBG was observed by scanning electron microscopy (SEM). Furthermore, E. faecalis biofilms on the three root canal sealers were labeled with a LIVE/DEAD BacLight ${ }^{\mathrm{TM}}$ Bacterial Viability Kit, and the ratios of viable to dead cells were analyzed using laser scanning microscopy operative software (Zen software).
\end{abstract}

Results: In the assays, after 1 and 7 days, the number of $E$. faecalis adhering to the root canal sealers or gutta-percha in FBS were significantly lower than those in TSBG $(P<0.05)$. In FBS, E. faecalis adhesion to iRoot SP and gutta-percha was reduced to a greater extent than that adhered to Apexit Plus and AH-Plus. Few E. faecalis accumulated on iRoot $\mathrm{SP}$ in FBS, whereas many bacteria assembled on iRoot SP and formed biofilms in TSBG. The ratio of viable cells in the $E$. faecalis biofilm on iRoot SP was the lowest.

Conclusions: Calcium hydroxide-based root canal sealers, epoxy resin sealers and bioceramic sealers may provide a substrate for E. faecalis adhesion, and the bioceramic sealer in this study showed the least E. faecalis adhesion in the presence of serum proteins compared to the other two sealers.

Keywords: Enterococcus faecalis, Root canal sealers, Fetal bovine serum

*Correspondence: tongzhch@mail.sysu.edu.cn

1 Department of Operative Dentistry and Endodontics, Guanghua School

of Stomatology, Sun Yat-Sen University, No 56, Lingyuan West Road,

Guangzhou 510055, Guangdong, China

Full list of author information is available at the end of the article

\begin{abstract}
Background
Adequate root canal obturation prevents bacterial invasion of the root canal space and is one of the key factors in successful endodontic treatment [1]. Although chemomechanical preparation and medicaments may remove most of the pathogenic bacteria from the root canal system, some areas, such as isthmuses, lateral canals, accessory canals, and other root canal irregularities, remain
\end{abstract}


untouched [2]. These untouched areas with residual bacteria will prevent the healing of periradicular lesions.

During root canal obturation, root canal sealers may entomb residual bacteria and act as disinfectants to prevent bacterial invasion [3, 4]. Among the current root canal sealers, the calcium hydroxide-based root canal sealer Apexit Plus and the tricalcium silicate-based bioceramic sealer iRoot SP have shown strong antimicrobial activities and excellent physical and biological properties; therefore, they have been widely applied for root canal obturation. An epoxy resin-based sealer, such as AH Plus, is generally accepted to be the gold standard against all new sealers due to its resorption resistance and dimensional stability [5-10]. Endodontic sealers possess antimicrobial activity against a range of common pathogenic microbes and provide a complete microscopic seal to impede bacterial invasion of the root canal system [3, 11-13]. However, gutta-percha points enclosed by endodontic sealers may still provide a substrate for bacterial adhesion despite their antibacterial activities. The extraradicular presence of the filling material may delay the healing of periradicular diseases or even cause treatment failure [14-16].

Gutta-percha and sealers are generally well tolerated on apical tissues in the absence of concomitant infection, and even in the presence of filling material extrusion, histological healing may still occur $[17,18]$. However, in the presence of extrusion of infected debris by overinstrumentation or infection in the periradicular tissues, the extruded gutta-percha and root canal sealers may serve as a biofilm reservoir for sustained infection of the periradicular area, which might contribute to a nonhealing outcome [19]. Enterococcus faecalis species are considered to be the predominant bacteria in root-filled teeth with therapy failure. Some studies have found E. faecalis and bacterial biofilms on gutta-percha filling materials obtained from teeth associated with refractory radicular periodontitis [5, 20, 21]. At present, studies regarding bacterial adhesion to root canal sealers as well as the antibacterial activities of these sealers have been evaluated in a common bacterial culture medium [5-7]. However, in vivo, the extruded gutta-percha and root canal sealer are located at the periradicular tissue. Therefore, to elucidate bacterial adhesion after material overfilling to the periradicular tissue, we need to investigate the effects of serum proteins on E. faecalis biofilm adhesion to the surface of gutta-percha coated with three common root canal sealers, Apexit Plus, AH-Plus and iRoot SP sealer.

\section{Methods}

\section{Bacterial culture}

Enterococcus faecalis OG1RF was selected as the test bacteria in this study. A culture of the bacteria from the freezer $\left(-80^{\circ} \mathrm{C}\right)$ was streaked onto brain-heart infusion agar (BHI; Difco Laboratories, Detroit, MI) plates and grown at $37{ }^{\circ} \mathrm{C}$ for $24 \mathrm{~h}$. A single colony of bacteria was inoculated into $5 \mathrm{~mL}$ of $\mathrm{BHI}$ broth and cultured at $37{ }^{\circ} \mathrm{C}$ under anaerobic conditions until the exponential phase of growth.

\section{Gutta-percha coating by the root canal sealers}

Three resin blocks with simulated curved root canals (Plastic Training Block V04 0245; VDW, Munich, Germany) were instrumented using a ProTaper system (Dentsply Maillefer, Ballaigues, Switzerland) up to F2 accompanied by irrigation with $3 \%$ sodium hypochlorite $(\mathrm{NaOCl})$ and $17 \%$ ethylenediaminetetraacetic acid (EDTA). The three prepared root canals were filled with $5.25 \% \mathrm{NaOCl}$ and disinfected for $10 \mathrm{~min}$. After being drying with sterile paper points, the three prepared root canals were filled with one of three root canal sealers: Apexit Plus (a calcium hydroxide-based root canal sealer, Ivoclar Vivadent, Liechtenstein), AH-Plus (Dentsply De Trey GmbH, Konstanz, Germany) or iRoot SP (a tricalcium silicate-containing sealer, Innovative BioCeramix Inc., Vancouver, $\mathrm{BC}$, Canada). After sterilization by soaking in $5.25 \% \mathrm{NaOCl}$ for $5 \mathrm{~min}$, nine ProTaper F2 guttapercha points were inserted into the three groups of root canals filled with sealer and rotated back and forth $360^{\circ}$ to ensure that the root canal sealer was evenly coated on the surface of the gutta-percha. After solidification, the gutta-percha with root canal sealer and the control guttapercha without sealer were cut off at the $10 \mathrm{~mm}$ site from the tip and placed in a 24-well microplate.

\section{Evaluation of bacterial adhesion}

To evaluate the effects of the root canal sealers on bacterial adhesion, $1.99 \mathrm{~mL}$ of tryptic soy broth supplemented with $1 \%$ glucose (TSBG) and $10 \mu \mathrm{L}$ of E. faecalis in the exponential growth phase were added to a 24-well microplate and incubated at $37^{\circ} \mathrm{C}$ for up to 1 day or 7 days. The culture was replaced with fresh medium every second day. After incubation, the four groups of gutta-percha points were removed and washed two times with sterile phosphate-buffered saline (PBS) solution to remove the unadhered cells. The gutta-percha points were then placed in a centrifuge tube containing $2 \mathrm{~mL}$ of sterile PBS and stored in an ice box. The adhesive bacteria were harvested by scraping and ultrasonic treatment and resuspended in PBS. Afterward, the bacterial suspension was consecutively diluted tenfold and spread on BHI agar plates. The colonies were counted, and the number of bacteria adhered to the four groups of gutta-percha was calculated. To evaluate the effects of serum proteins on bacterial adhesion, the same four groups of gutta-percha were immersed in $1.99 \mathrm{~mL}$ of fetal bovine serum (FBS; 
HyClone, America) and $10 \mu \mathrm{L}$ of $E$. faecalis in the exponential growth phase, and the same bacterial adhesive assay was performed. Each test was carried out at least 3 times on different days.

\section{Scanning electron microscopy}

The three groups of gutta-percha points with root canal sealers and a control gutta-percha point without sealer were prepared, and 7 days of $E$. faecalis adhesion in TSBG or FBS was completed according to the above procedure. The gutta-percha specimens were fixed in $2.5 \%$ glutaraldehyde and dehydrated in a series of acetonitrile solutions $(50 \%, 70 \%, 80 \%$, and $90 \%$ for 20 min each and $100 \%$ for 20 min twice) after being rinsed twice with sterile PBS. The specimens were dried and then sputtered with gold. E. faecalis biofilms on the surface of the gutta-percha points were observed by scanning electron microscopy (SEM; E-1010, Hitachi, Ibaraki, Japan).

\section{Confocal laser scanning microscopy}

The Apexit Plus, AH-Plus and iRoot SP sealers were evenly coated on the surface of a $10-\mathrm{mm}$ diameter cover glass. After solidification at $37{ }^{\circ} \mathrm{C}$, the cover glasses were immersed in FBS for $2 \mathrm{~h}$ in a 24-well microplate. The cover glasses without sealers were referred to as the control. The four groups of cover glasses were transferred to another well, and $1.99 \mathrm{~mL}$ of TSBG and $10 \mu \mathrm{L}$ of $E$. faecalis in the exponential growth phase were added. After incubation at $37{ }^{\circ} \mathrm{C}$ for 7 days, the bacterial biofilms on the surfaces of the root canal sealers were gently washed twice with PBS. Subsequently, the cover glasses with bacterial biofilms were transferred to Petri dishes with glass bottoms (D: 35 mm, Hangzhou Shengyou Biotechnology, China) and stained with SYTO 9 and propidium iodide
(PI) at room temperature in the dark for 15 min according to the specifications of the L7012 kit (LIVE/DEAD Bac-Light Bacterial Viability Kit; Molecular Probes, Eugene, OR). The Petri dishes were then clamped, and bacterial biofilms were scanned with a Carl Zeiss confocal laser scanning microscopy (CLSM) instrument. SYTO 9 and PI were excited at $488 \mathrm{~nm}$ and $543 \mathrm{~nm}$, respectively. Three-dimensional biofilms were captured along the $\mathrm{Z}$ axis, and the ratio of viable and dead cells in each biofilm was calculated by ZEN software (ZEN 2012 light edition, Carl Zeiss MicroImaging, Inc., Thornwood, NY), which is a modular image acquisition, processing and analysis software for digital microscopy.

\section{Statistical analysis}

Statistical analysis was performed using SPSS 20.0 software. The number of $E$. faecalis adhesions on the surfaces of the three root canal sealers and the control group were compared using one-way ANOVA and Tukey's HSD tests. A $P$ value $<0.05$ was considered statistically significant.

\section{Results}

Effects of the sealers on bacterial adhesion

On both Days 1 (Fig. 1a) and 7 (Fig. 1b), the amount of E. faecalis adhering to Apexit Plus, iRoot SP and guttapercha in TSBG was significantly greater than that in FBS $(P<0.05)$, and there was no significant difference between the amount of E. faecalis adhering to AH-Plus in TSBG and FBS on Day $7(P>0.05)$. E. faecalis adhesion to Apexit Plus was significantly greater than that to iRoot SP and gutta-percha in FBS $(P<0.05)$ on Days 1 and 7 . E. faecalis adhesion to AH-Plus was significantly greater than that to the iRoot SP and gutta-percha in FBS only on
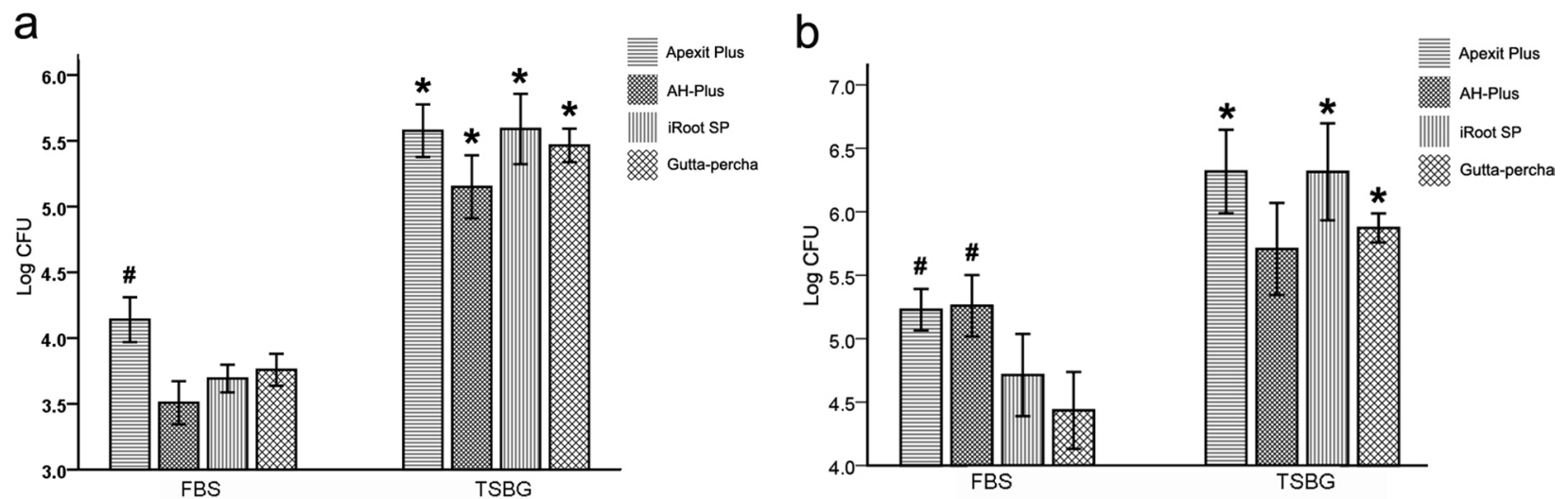

Fig. 1 The amount of E. faecalis adhering to Apexit Plus, AH-Plus, iRoot SP and gutta-percha alone in FBS or TSBG medium for 1 day (a) and 7 days (b). "*" represents a significant difference between the amount of E. faecalis adhered to the same sealer in FBS and TSBG media ( $P<0.05)$. "\#" represents a significant difference compared to the amount of $E$. faecalis adhered to gutta-percha alone in the same medium $(P<0.05)$ 
Day 7. The four groups exhibited no significant difference in TSBG $(P>0.05)$. Whether in FBS or in TSBG, of the amount of $E$. faecalis adhesion after 7 days was greater than that after 1 day of adhesion in the four groups (Fig. 1).

\section{Morphology of bacterial biofilm adhesion to the surface of the sealers and gutta-percha}

Gutta-percha coated with three root canal sealers and the control gutta-percha without sealer were observed by SEM after being immersed in FBS and TSBG medium for 7 days. Few bacteria adhered to iRoot SP and gutta-percha, and the masses of the bacteria aggregated on Apexit Plus and AH-Plus in FBS medium (Fig. 2). In TSBG medium, a number of $E$. faecalis aggregated on Apexit Plus and iRoot SP and showed a typical biofilm structure (Fig. 3e, g). A small amount of relatively loose E. faecalis adhered to AH-Plus (Fig. 3f). Furthermore, a few E. faecalis were dispersedly adhered to the gutta-percha and did not form a biofilm structure (Fig. 3h).

\section{Antibacterial activities of the three root sealers on Enterococcus faecalis biofilms}

Images of 3-dimensional E. faecalis biofilms on the surfaces of the root canal sealers are shown in Fig. 4. For the control, E. faecalis biofilms mostly showed green live bacteria. Red dead bacteria were found on the surface of the three root canal sealers, and the percentages of dead bacteria on the iRoot SP sealer were the highest among the three groups of root canal sealers.

\section{Discussion}

Filling materials should be restricted to the intraradicular space during root canal obturation, and endodontic treatment with root canal fillings ending within $2 \mathrm{~mm}$ of the scope of the radiographic apex show a high success rate [22]. However, the extrusion of root canal filling materials occasionally occurs due to incorrect operations, anatomical factors, and material properties, among other factors. Extruded filling materials may affect the treatment outcome, and a significantly worse outcome has been observed for teeth with apical periodontitis in comparison with teeth with no lesions [17]. Extrusion not only causes an inflammatory response but also provides a substrate for bacterial adhesion [23, 24]. Although filling root canal sealers have antibacterial activities, some bacteria, such as E. faecalis, still adhere to the surface of the materials [5, 25]. Our studies indicated that E. faecalis may adhere to the surface of Apexit Plus, AH-Plus, iRoot SP, and gutta-percha. Notably, substrate of overfilling might be conducive to the formation of bacterial biofilms and further hinder the healing of apical periodontitis.

The antibacterial activities of root canal sealers against E. faecalis have mostly been measured by bacterial growth in common medium [13, 26-28]. In these tests, the root canal sealers showed different antibacterial activities. A study by Bukhari et al. showed that Endosequence $\mathrm{BC}$ (which is the same sealer as iRoot SP marketed under a different brand name) killed significantly more 8-weekold E. faecalis in biofilms attached to the canal surfaces when compared with AH-Plus by confocal laser scanning
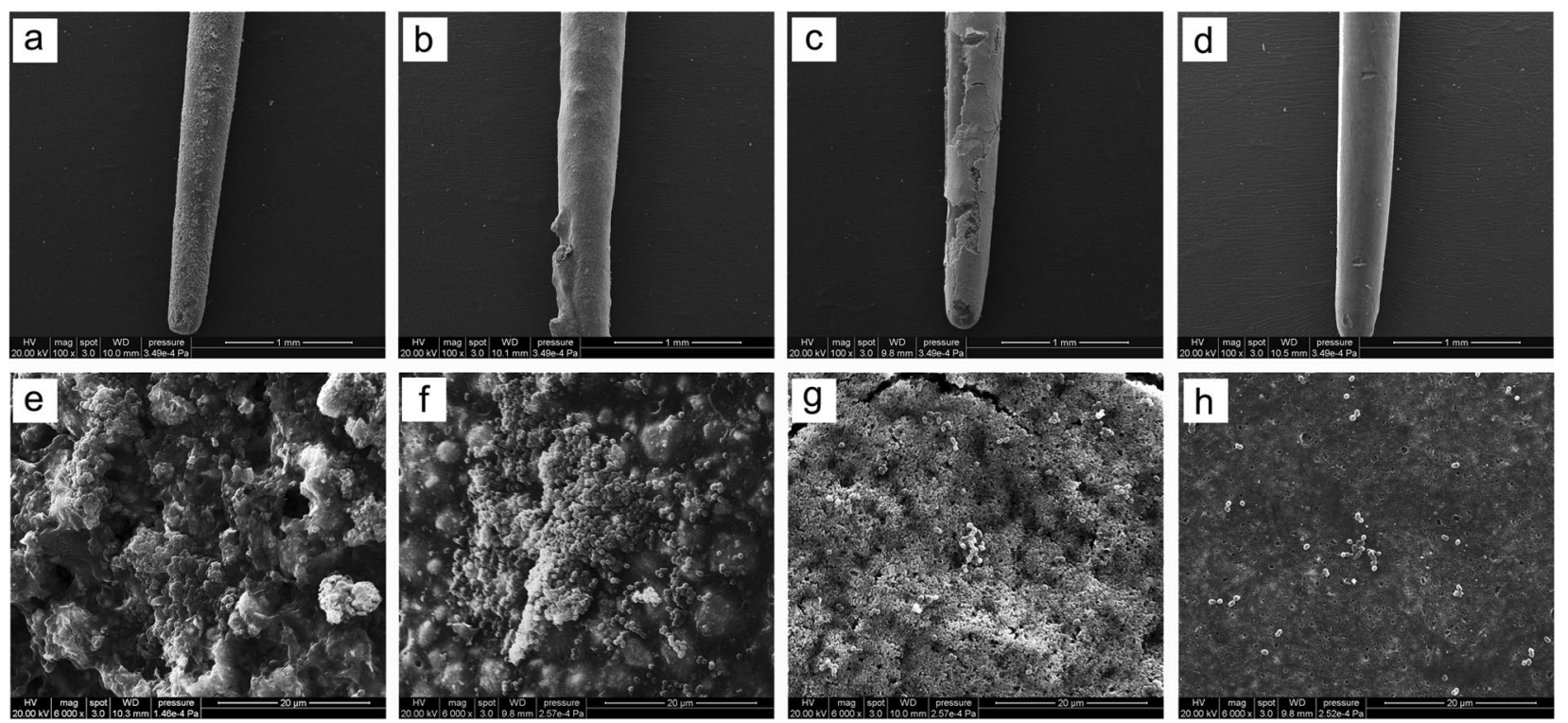

Fig. 2 E. faecalis adhesion to Apexit Plus (a) and (e), AH-Plus (b) and (f), iRoot SP (c) and (g), and gutta-percha points (d) and (h) in FBS medium. $\mathbf{a}-\mathbf{d} \times 100$ magnification and $\mathbf{e}-\mathbf{h}$ show $\times 6000$ magnification 

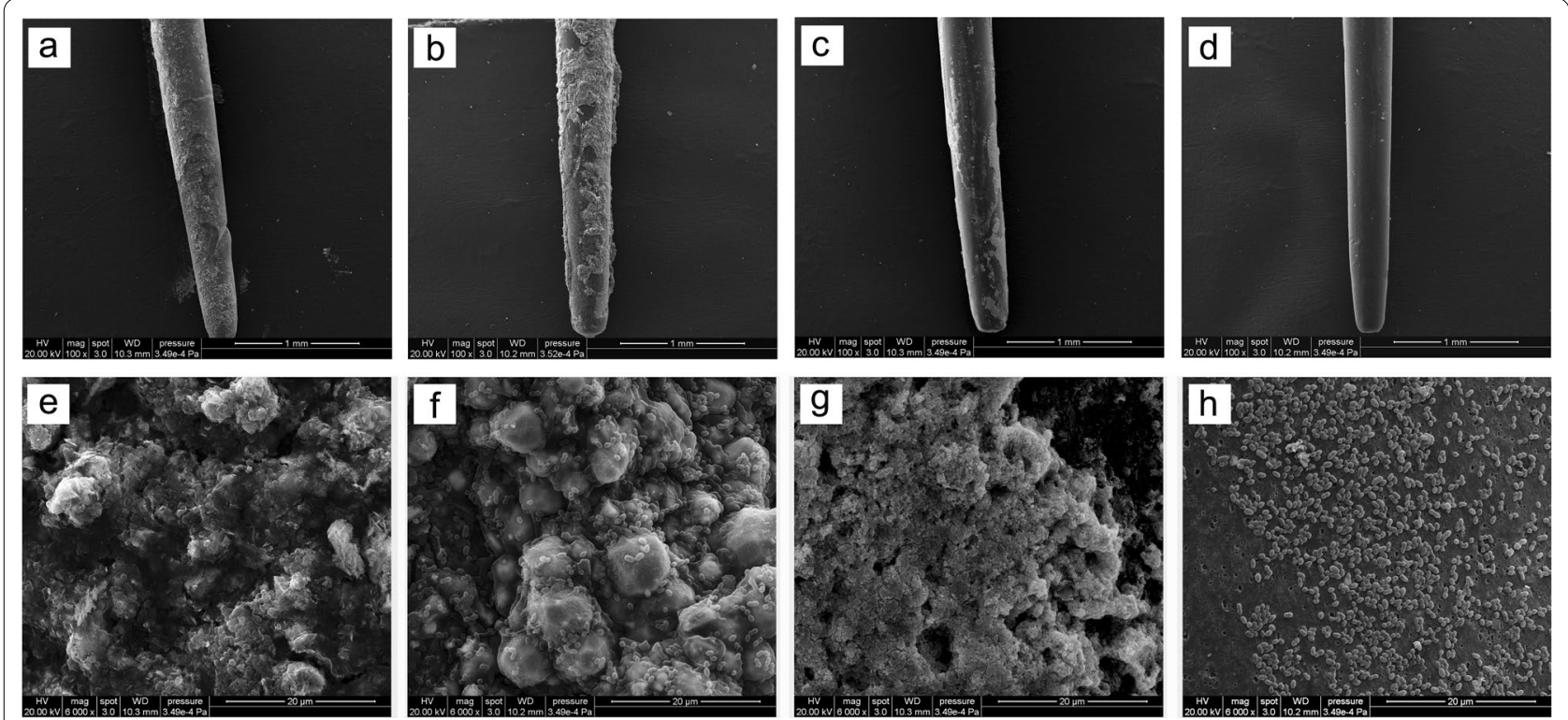

Fig. 3 E. faecalis adhesion to the surfaces of Apexit Plus (a) and (e), AH-Plus (b) and (f), iRoot SP (c) and (g), and gutta-percha points (d) and (h) in TSBG medium. $\mathbf{a}-\mathbf{d} \times 100$ magnification and $\mathbf{e}-\mathbf{h}$ show $\times 6000$ magnification

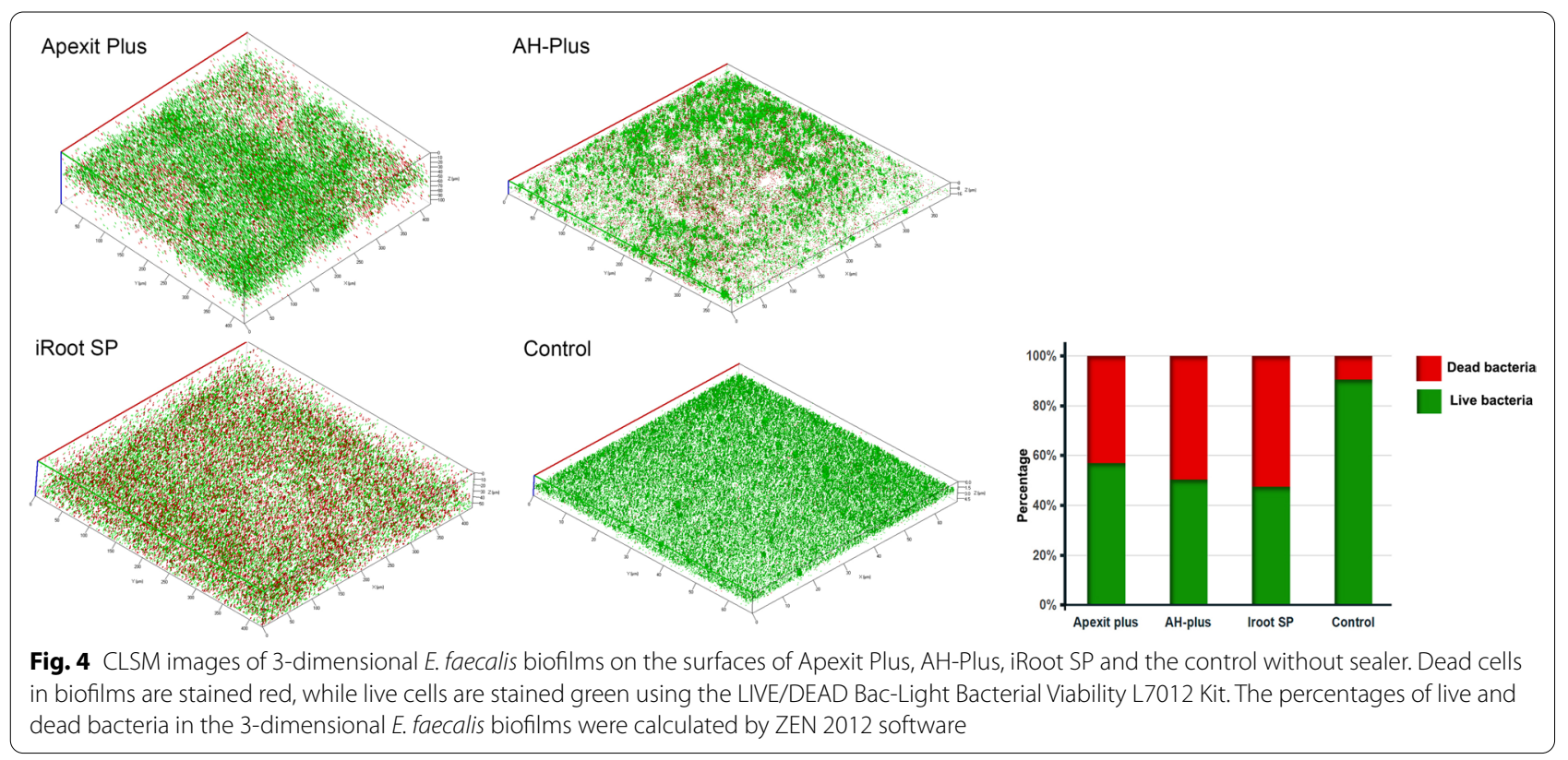

microscopy analysis [13]. Candeiro et al. showed no bacterial growth from 24to $168 \mathrm{~h}$ in the medium after the insertion of $\mathrm{AH}$-Plus or $\mathrm{BC}$ sealer by using a direct contact test (DCT) [23]. To determine the antibacterial activities of root canal sealers, DCTs are often employed. However, when the root canal sealers or gutta-percha are overfilled in the periradicular tissues, the amount of bacteria adhered to the root canal sealers cannot be tested by DCT only due to the existence of tissue fluid. The effects of the proteins in tissue fluid on the antibacterial activities of the tested drugs was evaluated by using FBS, human serum and BSA [29-31]. When extruded materials exist in periradicular tissues, the antibacterial action of the root canal sealers may not be the same as those obtained from in vitro tests in bacterial medium. Our studies showed that the amount of $E$. faecalis adhering to 
the three root canal sealers and gutta-percha was lower in FBS than in TSB. Root canal sealer dissolves as a result of contact with serum-like fluid or bacterial medium, and interstices are made, which allows bacterial adhesion. Epoxy resin sealers are generally considered to be difficult to dissolve $[9,10]$, and thus, there was no significant difference between the amount of $E$. faecalis adhesion to AH-Plus in FBS or TSB at 7 days. However, calcium hydroxide-based root canal sealers and bioceramic sealers may dissolve slightly and produce greater porosities $[32,33]$. TSBG is a nutrient-rich medium that includes many proteins and carbohydrates, and it has benefits against bacterial growth and adhesion. Serum proteins mostly provide an organic monolayer film on root canal sealers to serve as an excellent anchor for bacterial adhesion. Calcium hydroxide-based root canal sealers and bioceramic sealers are more strongly dissolved in TBS because FBS is a slightly viscous liquid. Thus, more $E$. faecalis adhered to Apexit Plus and iRoot SP in TSBG than in FBS.

The amount of E. faecalis adhering to AH-Plus significantly decreased in FBS on day one, and the bacterial amount increased on Day 7, which was consistent with the Kapralos et al. study. E. faecalis tested on the surface of the root canal sealers coated on gutta-percha in our studies and E. faecalis counts by a modified DCT assay in the Kapralos et al. study both showed that AH Plus had high antibacterial activity on day one, and the antibacterial activity decreased over 7 days despite the different test methods [11]. The amount of viable E. faecalis was reduced on the surface of iRoot SP compared to that of AH-Plus on Day 7, which indicated that the bioceramic sealers showed durable antibacterial activities against $E$. faecalis. Freshly mixed root canal sealers are often considered to have certain antimicrobial activity against $E$. faecalis, although the antimicrobial activity was lost as the material set with the exception of the bioceramic sealers [34].

Gutta-percha is the most popular core material used for root canal obturation. In our study, few E. faecalis adhered to the gutta-percha without sealers in the presence of FBS, and the amount of bacterial adhesion after 7 days was the least in the four test groups on guttapercha alone. The relatively smooth surface of guttapercha did not benefit bacterial adhesion. Gutta-percha cones consist of approximately $20 \%$ gutta-percha, $65 \%$ zinc oxide, $10 \%$ radiopacifiers, and $5 \%$ plasticizers, and attempts have been made to make gutta-percha antimicrobial by the addition of antibacterial materials [3538], which will further decrease bacterial adhesion. In George et al.s studies, when E. faecalis 29212 was inoculated, no significant biofilm formation was detected at the gutta-percha points conditioned with serum for
2 weeks under nutrient-deprived conditions, similar to our results [39]. However, in the study by Takemura et al., a significant bacterial biofilm formed on the gutta-percha points when E. faecalis 6-2L was used as the test bacteria in media containing $45 \%$ and $90 \%$ serum [40]. These different results might be related to the pretreatment of the gutta-percha points. The gutta-percha points were sterilized by soaking in $5.25 \% \mathrm{NaOCl}$ for 5 min before evaluation in our study, and pretreatment with $\mathrm{NaOCl}$ significantly reduced E. faecalis formation on guttapercha points [41]. Therefore, bacterial adhesion to the gutta-percha points was influenced by multiple factors, such as the bacterial strains, nutrition, disinfectants, and infection time.

An in vitro study investigated the effects of serum proteins on E. faecalis adhesion to the surface of three root canal sealers coated on gutta-percha. The extrusion of root canal sealers or gutta-percha in periradicular tissues initiates inflammatory reactions [42, 43]. The immune response by the overfilled materials and bacterial clearance of the immune system also influence bacterial adhesion to the sealers and gutta-percha. Therefore, future studies on the effects of bacterial adhesion to the extruded materials on periapical tissue should be considered in combination with serum proteins and host immune cells.

\section{Conclusion}

Within the limitations of this study, despite the antibacterial action of a calcium hydroxide-based root canal sealer, an epoxy resin sealer and a bioceramic sealer, E. faecalis may still adhere to the surface of these three root canal sealers coated on gutta-percha. Serum proteins significantly reduced the amount of E. faecalis adhered to the three types of root canal sealers, and E. faecalis showed less adhesion to the bioceramic sealer and gutta-percha alone than the calcium hydroxide-based root canal sealer and epoxy resin sealer in the presence of serum proteins.

\section{Abbreviations \\ FBS: Fetal bovine serum; TSBG: Tryptic soy broth supplemented with $1 \%$ glu- cose; NaOCl: Sodium hypochlorite; SEM: Scanning electron microscopy; CLSM: Confocal laser scanning microscopy.}

\section{Acknowledgements \\ Not applicable.}

Authors' contributions

TZ: study design, data assessment, manuscript revision, final manuscript approval, funding. LX and CD: experiments performance, data analysis and collection, manuscript drafting. GQ: data analysis, manuscript revision and funding. All authors read and approved the final manuscript.

\section{Funding}

This study was supported by the National Natural Science Foundation of China (grant no. 81870750) and the Guangdong Financial Fund for HighCaliber Hospital Construction (174-2018-XMZC-0001-03-0125/C-5). 


\section{Availability of data and materials}

All data generated or analyzed during this study are included in this published article.

\section{Declarations}

Ethics approval and consent to participate

Not applicable.

\section{Consent to publication}

Not applicable.

\section{Competing interests}

The authors declare that they have no conflicts of interest.

\section{Author details}

'Department of Operative Dentistry and Endodontics, Guanghua School of Stomatology, Sun Yat-Sen University, No 56, Lingyuan West Road, Guangzhou 510055, Guangdong, China. ${ }^{2}$ Guangdong Provincial Key Laboratory of Stomatology, Sun Yat-Sen University, Guangzhou, Guangdong, China.

\section{Received: 27 April 2021 Accepted: 26 November 2021}

\section{Published online: 07 December 2021}

\section{References}

1. Donnermeyer D, Vahdat-Pajouh N, Schafer E, et al. Influence of the final irrigation solution on the push-out bond strength of calcium silicatebased, epoxy resin-based and silicone-based endodontic sealers. Odontology. 2019;107(2):231-6.

2. Nosrat A, Verma P, Hicks ML, et al. Variations of palatal canal morphology in maxillary molars: a case series and literature review. J Endod. 2017;43(11):1888-96.

3. Komabayashi T, Colmenar D, Cvach N, et al. Comprehensive review of current endodontic sealers. Dent Mater J. 2020;39(5):703-20.

4. Salz U, Poppe D, Sbicego S, et al. Sealing properties of a new root canal sealer. Int Endod J. 2009:42(12):1084-9.

5. Senges C, Wrbas KT, Altenburger M, et al. Bacterial and Candida albicans adhesion on different root canal filling materials and sealers. J Endod. 2011;37(9):1247-52

6. Alsubait S, Albader S, Alajlan N, et al. Comparison of the antibacterial activity of calcium silicate- and epoxy resin-based endodontic sealers against Enterococcus faecalis biofilms: a confocal laser-scanning micros copy analysis. Odontology. 2019;107(4):513-20.

7. Huang $Y, L i X$, Mandal $P$, et al. The in vitro antimicrobial activities of four endodontic sealers. BMC Oral Health. 2019;19(1):118.

8. Lee JK, Kwak SW, Ha JH, et al. Physicochemical properties of epoxy resin-based and bioceramic-based root canal sealers. Bioinorg Chem Appl. 2017;2017:2582849.

9. Schafer E, Zandbiglari T. Solubility of root-canal sealers in water and artificial saliva. Int Endod J. 2003;36(10):660-9.

10. Donnelly A, Sword J, Nishitani Y, et al. Water sorption and solubility of methacrylate resin-based root canal sealers. J Endod. 2007;33(8):990-4

11. Kapralos V, Koutroulis A, Orstavik D, et al. Antibacterial Activity of endodontic sealers against planktonic bacteria and bacteria in biofilms. J Endod. 2018:44(1):149-54.

12. Gallusi G, Campanella V, Montemurro E, et al. Antibacterial activity of first and latest generation bioceramic sealers on the elimination of enterococcus faecalis: an in vitro study. J Biol Regul Homeost Agents. 2020;34(3 Suppl. 1):73-9

13. Bukhari $S$, Karabucak B. The antimicrobial effect of bioceramic sealer on an 8-week matured Enterococcus faecalis biofilm attached to root canal dentinal surface. J Endod. 2019:45(8):1047-52.

14. Molven $\mathrm{O}$, Halse A, Fristad I, et al. Periapical changes following rootcanal treatment observed 20-27 years postoperatively. Int Endod J. 2002;35(9):784-90
15. Nair PN, Sjogren U, Krey G, et al. Therapy-resistant foreign body giant cell granuloma at the periapex of a root-filled human tooth. J Endod. 1990;16(12):589-95.

16. Sjogren U, Sundqvist G, Nair PN. Tissue reaction to gutta-percha particles of various sizes when implanted subcutaneously in guinea pigs. Eur J Oral Sci. 1995;103(5):313-21.

17. Ricucci D, Rocas IN, Alves FR, et al. Apically extruded sealers: fate and influence on treatment outcome. J Endod. 2016;42(2):243-9.

18. Fristad I, Molven $\mathrm{O}$, Halse A. Nonsurgically retreated root filled teethradiographic findings after 20-27 years. Int Endod J. 2004;37(1):12-8.

19. Bjorndal L, Amaloo C, Markvart M, et al. maxillary sinus impaction of a core carrier causing sustained apical periodontitis, sinusitis, and nasal stenosis: a 3-year follow-up. J Endod. 2016;42(12):1851-8.

20. Guerreiro-Tanomaru JM, de Faria-Junior NB, Duarte MA, et al. Comparative analysis of Enterococcus faecalis biofilm formation on different substrates. J Endod. 2013:39(3):346-50.

21. Noiri Y, Ehara A, Kawahara T, et al. Participation of bacterial biofilms in refractory and chronic periapical periodontitis. J Endod. 2002;28(10):679-83.

22. Schaeffer MA, White RR, Walton RE. Determining the optimal obturation length: a meta-analysis of literature. J Endod. 2005;31(4):271-4.

23. Candeiro GTM, Moura-Netto C, D'Almeida-Couto RS, et al. Cytotoxicity, genotoxicity and antibacterial effectiveness of a bioceramic endodontic sealer. Int Endod J. 2016;49(9):858-64.

24. Yoshino P, Nishiyama CK, Modena KC, et al. In vitro cytotoxicity of white MTA, MTA Fillapex(R) and Portland cement on human periodontal ligament fibroblasts. Braz Dent J. 2013:24(2):111-6.

25. $\mathrm{Xu} \mathrm{J,} \mathrm{He} \mathrm{J,} \mathrm{Shen} \mathrm{Y,} \mathrm{et} \mathrm{al.} \mathrm{Influence} \mathrm{of} \mathrm{endodontic} \mathrm{procedure} \mathrm{on} \mathrm{the} \mathrm{adher-}$ ence of Enterococcus faecalis. J Endod. 2019:45(7):943-9.

26. Beyth N, Kesler-Shvero D, Zaltsman N, et al. Rapid kill-novel endodontic sealer and Enterococcus faecalis. PLoS ONE. 2013;8(11):785.

27. Bodrumlu E, Semiz M. Antibacterial activity of a new endodontic sealer against Enterococcus faecalis. J Can Dent Assoc. 2006;72(7):637.

28. Hoelscher AA, Bahcall JK, Maki JS. In vitro evaluation of the antimicrobial effects of a root canal sealer-antibiotic combination against Enterococcus faecalis. J Endod. 2006:32(2):145-7.

29. Crabbe A, Liu Y, Matthijs N, et al. Antimicrobial efficacy against Pseudomonas aeruginosa biofilm formation in a three-dimensional lung epithelial model and the influence of fetal bovine serum. Sci Rep. 2017:7:43321

30. Pappen FG, Qian W, Aleksejuniene J, et al. Inhibition of sodium hypochlorite antimicrobial activity in the presence of bovine serum albumin. J Endod. 2010;36(2):268-71

31. Tong Z, Zhang $Y$, Wei $X$. The effect of human serum and dentin powder alone or in combination on the antibacterial activity of sodium hypochlorite against Enterococcus faecalis. Arch Oral Biol. 2019;97:72-6.

32. Torres FFE, Guerreiro-Tanomaru JM, Bosso-Martelo R, et al. Solubility, Porosity, Dimensional and Volumetric Change of Endodontic Sealers. Braz Dent J. 2019:30(4):368-73.

33. McMichen FR, Pearson G, Rahbaran S, et al. A comparative study of selected physical properties of five root-canal sealers. Int Endod J. 2003;36(9):629-35.

34. AlShwaimi $E$, Bogari $D$, Ajaj $R$, et al. In vitro antimicrobial effectiveness of root canal sealers against Enterococcus faecalis: a systematic review. J Endod. 2016:42(11):1588-97.

35. Chogle S, Mickel AK, Huffaker SK, et al. An in vitro assessment of iodoform gutta-percha. J Endod. 2005;31(11):814-6.

36. Lohbauer U, Gambarini G, Ebert J, et al. Calcium release and pH-characteristics of calcium hydroxide plus points. Int Endod J. 2005;38(10):683-9.

37. Lui JN, Sae-Lim V, Song KP, et al. In vitro antimicrobial effect of chlorhexidine-impregnated gutta percha points on Enterococcus faecalis. Int Endod J. 2004:37(2):105-13.

38. Melker KB, Vertucci FJ, Rojas MF, et al. Antimicrobial efficacy of medicated root canal filling materials. J Endod. 2006:32(2):148-51.

39. George S, Basrani B, Kishen A. Possibilities of gutta-percha-centered infection in endodontically treated teeth: an in vitro study. J Endod. 2010;36(7):1241-4

40. Takemura N, Noiri Y, Ehara A, et al. Single species biofilm-forming ability of root canal isolates on gutta-percha points. Eur J Oral Sci. 2004;112(6):523-9. 
41. Ravi Chandra PV, Kumar VH, Reddy SJ, et al. Biofilm forming capacity of Enterococcus faecalis on Gutta-percha points treated with four disinfectants using confocal scanning laser microscope: an in vitro study. Dent Res J (Isfahan). 2015;12(4):331-6.

42. Braga JM, Oliveira RR, de Castro MR, et al. Assessment of the cytotoxicity of a mineral trioxide aggregate-based sealer with respect to macrophage activity. Dent Traumatol. 2015:31(5):390-5.
43. Bernath M, Szabo J. Tissue reaction initiated by different sealers. Int Endod J. 2003;36(4):256-61.

\section{Publisher's Note}

Springer Nature remains neutral with regard to jurisdictional claims in published maps and institutional affiliations.
Ready to submit your research? Choose BMC and benefit from:

- fast, convenient online submission

- thorough peer review by experienced researchers in your field

- rapid publication on acceptance

- support for research data, including large and complex data types

- gold Open Access which fosters wider collaboration and increased citations

- maximum visibility for your research: over $100 \mathrm{M}$ website views per year

At BMC, research is always in progress.

Learn more biomedcentral.com/submissions 